\title{
Tumor de colisão de pele do pescoço
}

\section{Neck skin collision tumor}

Helma Maria Chedid ${ }^{1}$; Aglailton dos Santos Menezes ${ }^{2}$; Kiyoshi Fernandes Aikawa ${ }^{2}$; Carlos Neutzling Lehn, ; Abrão Rapoport - ECBC-SP1; Ana Maria da Cunha Mercante ${ }^{3}$; Otávio Alberto Curioni - TCBC-SP4

\section{R E S U M O}

O tumor de colisão ou tumor misto é uma neoplasia maligna de pele, relacionada à exposição solar e com índices de incidência de até $1,5 \%$. Apresenta comportamento clínico peculiar, em relação às demais neoplasias malignas de pele e com diagnóstico histológico, caracterizado pela colisão entre um carcinoma basocelular e um carcinoma epidermóide, ou seja, duas neoplasias com histologias distintas e interface nítida entre ambas. O caso relatado foi de paciente do sexo masculino, 73 anos, com duas lesões cervicais de crescimento progressivo nos últimos meses. O tratamento realizado foi cirúrgico, com exame histológico demonstrando a presença de carcinoma de células escamosas contíguo ao carcinoma de células basais. O acometimento preferencial ocorre em homens de pele clara, na quinta ou sexta décadas de vida. Sua localização mais comum é na cabeça e pescoço, principalmente na parte central da face. O carcinoma basoescamoso é diagnóstico diferencial, definido através de critérios histológicos distintos, uma vez que ambas neoplasias apresentam comportamento clínico semelhante. Os índices de recidiva local variam de $12 \%$ a $45 \%$, enquanto que é baixo na recidiva regional, de aproximadamente $7,5 \%$. Os principais fatores prognósticos são o gênero do paciente, margens cirúrgicas, infiltração perineural e status linfonodal. O tratamento de escolha é a ressecção, sendo a radioterapia indicada na sua adjuvância e lesões irressecáveis. A recidiva local é o principal fator limitante na sobrevida livre de doença que apresenta resultados pobres.

Descritores: Carcinoma basoescamoso. Neoplasias cutâneas. Neoplasias de cabeça e pescoço.

\section{INTRODUÇÃO}

$\mathrm{O}$ carcinoma basocelular é uma neoplasia maligna de pele, representando o tipo histológico mais frequente'. Semelhante ao carcinoma epidermoide de localização topográfica na pele, tem apresentação clínica, comportamento biológico e histológico peculiar, sendo entidade nosológica bem definida. Todavia, determinados carcinomas de pele exibem características histológicas de ambos os tipos, os carcinomas basocelular e epidermóide, com histogênese e comportamento biológico controverso. Recebem a denominação de carcinoma basoescamoso ou carcinoma basocelular metatípico². Representam incidência significativamente inferior dentre as neoplasias malignas de pele, apresentando comportamento biológico peculiar com maior agressividade, quando comparado ao carcinoma basocelular. Há evidências histológicas a favor de histogênese intermediária entre ambos tipos de carcinoma, basocelular e epidermóide ou que representem um tumor com ambos tipos histológicos, com uma transição nítida entre ambos. Estes recebem a denominação de tumores de colisão ${ }^{3}$.
A primeira descrição do carcinoma basoescamoso é atribuída a MacCormac ${ }^{4}$, em 1910. É um tumor de incidência rara, responsável por menos de $2 \%$ de todas as neoplasias malignas de pele 5 . Tem comportamento biológico representado por maior agressividade local, mesmo na vigência de ressecção com margens de segurança e potencial de metastatização ${ }^{6-8}$. A teoria mais aceita de sua histogênese é de um carcinoma basocelular pré-existente com áreas de diferenciação escamosa. Nos últimos anos, a hipótese difundida para o carcinoma basoescamoso é a presença de células totipotentes no carcinoma basocelular, responsáveis pela diferenciação em células escamosas. Tal diferenciação escamosa é a responsável pelo comportamento clínico de maior agressividade local. As áreas de diferenciação escamosa são consideradas estruturas celulares metatípicas ${ }^{9}$. Daí que a denominação de carcinoma metatípico é considerada como sinônimo de carcinoma basoescamoso ${ }^{1,9,10}$. Alguns autores são contra esse conceito e consideram o carcinoma basoescamoso como uma variante do carcinoma basocelular2,11.

O tumor de colisão é caracterizado pela colisão entre um carcinoma basocelular e um carcinoma

Trabalho realizado no Departamento de Cirurgia de Cabeça e Pescoço e Otorrinolaringologia do Hospital Heliópolis - Hosphel, São Paulo- SP-BR. 1. Cirurgiões do Departamento de Cirurgia de Cabeça e Pescoço e Otorrinolaringologia Hospital Heliópolis - Hosphel, São Paulo- SP-BR; 2. Residente do Departamento de Cirurgia de Cabeça e Pescoço e Otorrinolaringologia Hospital Heliópolis - Hosphel, São Paulo-SP-BR; 3. Chefe do Serviço de Anatomia patológica do Hospital Heliópolis - Hosphel, São Paulo- SP-BR; 4. Chefe do Departamento de Cirurgia de Cabeça e Pescoço e Otorrinolaringologia do Hospital Heliópolis - Hosphel, São Paulo- SP-BR. 
epidermoide puros, distinto do carcinoma basoescamoso pela zona de transição entre os dois tipos hitológicos. Recebe também a denominação de tumor misto ${ }^{4}$. A descrição do caso foi atribuída à raridade do tumor de colisão, padrão de crescimento semelhante ao carcinoma basocelular e às poucas séries na literatura demonstrando o diagnóstico inicial e a escolha do tratamento ideal.

\section{ASPECTOS TÉCNICOS}

Homem, 73 anos de idade, branco, solteiro, trabalhador da construção civil, natural do Ceará e residente em São Paulo há 50 anos. Na admissão, relato de ferida no pescoço há cinco anos e com crescimento progressivo nos últimos meses. Negava perda de peso, nódulo cervical e outros sintomas. No exame físico geral, apresentava-se de bom estado geral, eutrófico, pele de cor clara e olhos castanhos escuros. No exame locorregional de vias aerodigestivas superiores (EVADS), não foi encontrada lesão. No pescoço, havia lesão ulceroinfiltrativa e vegetante de $11,0 \times 4,0 \mathrm{~cm}$ na pele do pescoço, estendendo-se para a região clavicular e manúbrio esternal, predominantemente para a esquerda, móvel em relação ao manúbrio e às clavículas e friável ao toque (Figura 1). Presença de outra lesão úlcerovegetante de $2,0 \mathrm{~cm}$ no de maior diâmetro na região cervical à esquerda e móvel em relação aos planos profundos (Figura 1). Ausência de linfonodos palpáveis significativos. A biópsia incisional da lesão de maior tamanho evidenciou carcinoma basoescamoso. A tomografia de tórax evidenciou ausência de envolvimento ósseo e de linfonodos regionais sugestivos de metástases.

O paciente foi submetido ao esvaziamento cervical seletivo dos níveis IV e $V$ à esquerda e ressecção das duas lesões com margens de segurança. As duas lesões apresentavam comprometimento do tecido celular subcutâneo, sendo que a de maior tamanho não comprometia a fáscia da musculatura pré-tireoideana, o periósteo da clavícula e do esterno. A lesão de menor tamanho restringia-se à gordura, profundamente (Figura 2). Foram recortadas margens do leito cirúrgico e enviadas ao exame de congelação que evidenciaram ausência de neoplasia (Figura 2). Foi utilizado retalho fasciocutâneo, o deltopeitoral, para fechamento da área cruenta da lesão de maior extensão. (Figura 3).

No terceiro dia de pós-operatório, diagnosticouse seroma recorrente na área de rotação do retalho que foi tratado com as medidas usuais e evoluiu sem maiores intercorrências.

A peça cirúrgica proveniente da operação, continha lesão maior de $12,5 \mathrm{~cm}$ no seu maior eixo, com infiltração de tecido adiposo e margens livres. A lesão de menor diâmetro apresentava $2,8 \mathrm{~cm}$ no seu maior eixo, infiltrando até derme profunda e com margens livres. 0 esvaziamento cervical seletivo não apresentou metástase regional nos 12 linfonodos dissecados. O tipo histológico

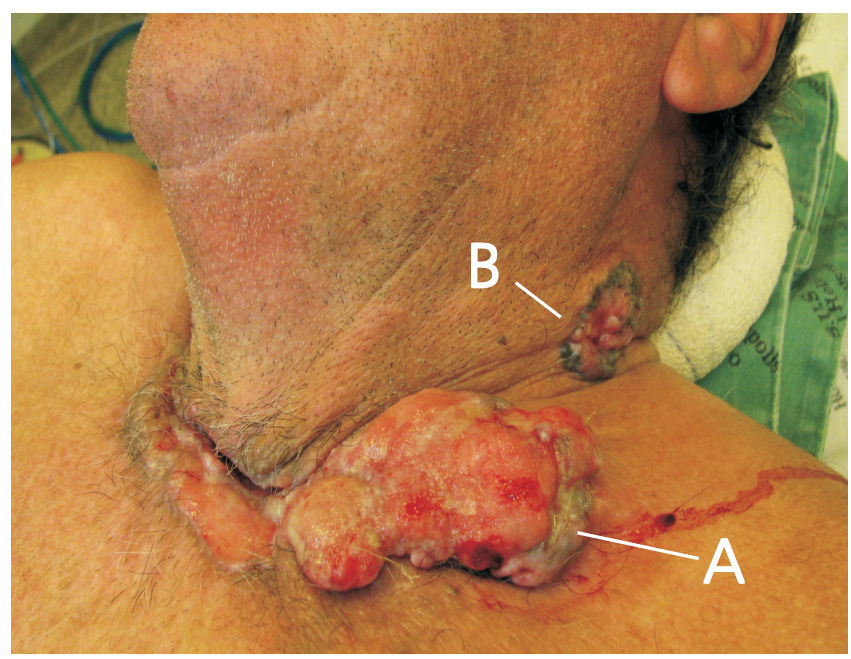

Figura 1 - Lesão ulcero-infiltrativa $(A)$ e lesão vegetante à es querda (B) na pele cervical.

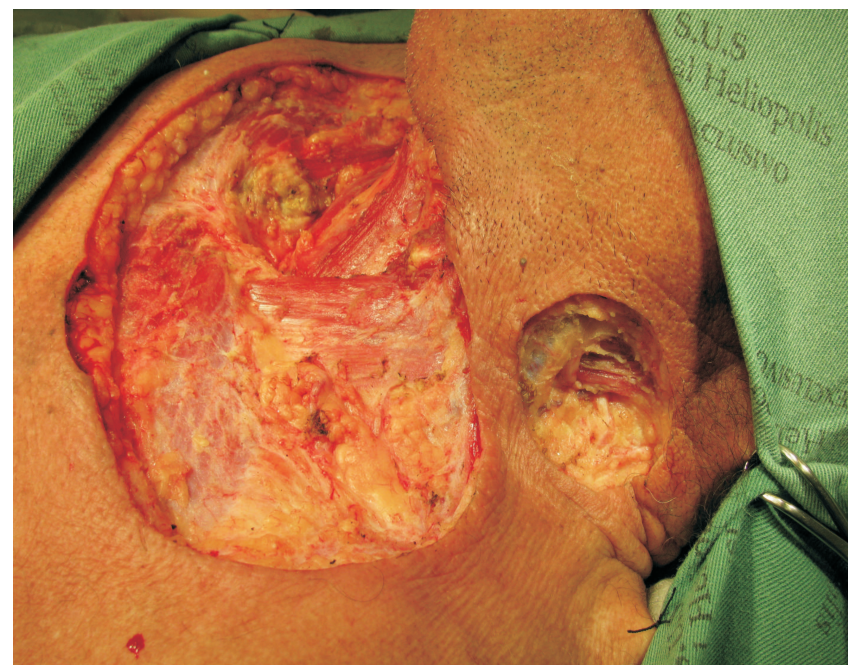

Figura 2 - Visão lateral esquerda, após a exérese das lesões cervicais.

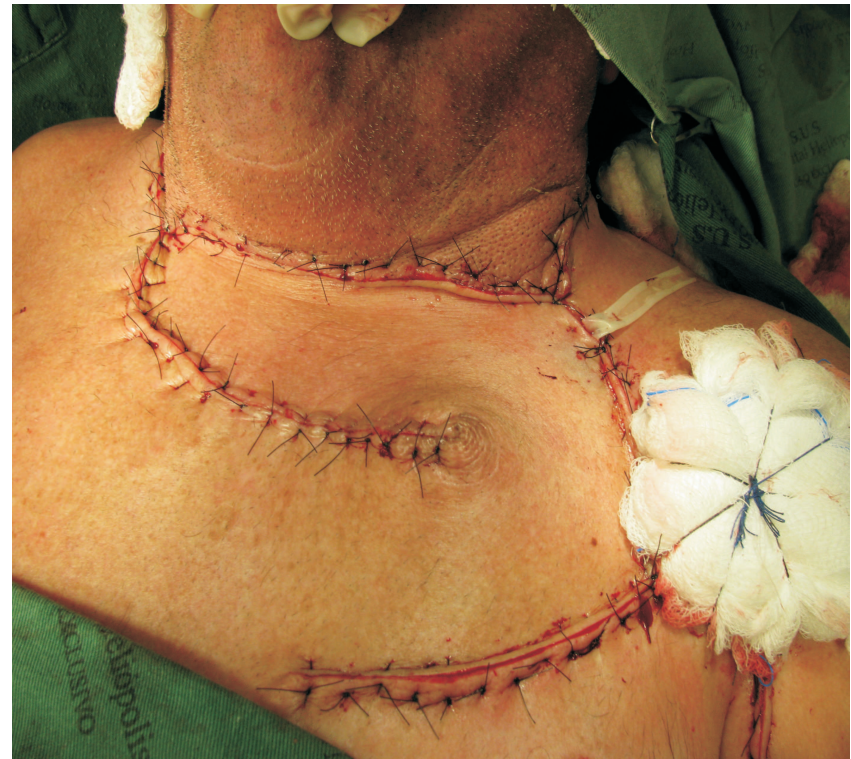

Figura 3 - $\quad$ Aspecto final do ato operatório, demonstrando o fechamento com a utilização do retalho deltopeitoral. 
das duas lesões confirmou o achado da biópsia incisional pré-operatória, de tumor de colisão, carcinoma epidermóide e carcinoma basocelular (Figura 4) separados por uma interface nítida na coloração de hematoxilina-eosina (HE). As margens recortadas estavam livres de comprometimento neoplásico. Ausência de infiltração perineural.

\section{DISCUSSÃO}

O carcinoma basoescamoso é considerado um tipo agressivo do carcinoma basocelular, com maior índice de recidiva local e metastatização. Este conceito tem sido favorecido na literatura, gerando terminologias diversas e controvérsias na sua histogênese. Tem predomínio nos indivíduos de pele clara com antecedente de exposição solar, predileção pelo gênero masculino e com incidência preferencial entre a quinta e oitava décadas. Todavia, há relato de casos a partir dos 25 anos até os 80 anos $^{5}$. Localização mais comum no segmento da cabeça e pescoço, especialmente, na parte central da face, com incidência de $82 \%$ a $97 \%$, atribuída a maior exposição solar²,6. As regiões anatômicas de maior distribuição são destacandose a pirâmide nasal (33\%), região auricular (18,5\%) e área periocular $(11,2 \%)^{2}$.

Na revisão da literatura, apesar da raridade, algumas séries demonstraram modelos histológicos compatíveis com as teorias propostas à histogênese do carcinoma basoescamoso. Borel ${ }^{6}$ relatou 35 casos dentre 1706 tumores malignos de pele não melanomas e Schüller et $a^{12}$, demonstraram 71 relatos em 2603 também tumores malignos de pele não melanomas.

O diagnóstico entre carcinoma basocelular e carcinoma basoescamoso é exclusivamente realizado pelo estudo histológico, através de biópsias incisionais, pois uma biópsia superficial ou de fragmento diminuto não evidenciam os dois tipos histológicos no mesmo tumor, atingindo índices de até $74 \%$ nos diagnósticos iniciais ${ }^{13}$. Sendo assim, recomenda-se o estudo da peça proveniente do procedimento cirúrgico, para diagnóstico mais fidedigno.
Leibovitch et $a^{1 / 3}$, demonstraram uma série de 178 casos no segmento da cabeça e pescoço, quando tratados inicialmente com exérese cirúrgica. As recidivas locais ocorreram em $47,8 \%$ dos pacientes, sendo que aproximadamente $70 \%$ apresentavam uma segunda recidiva. O diagnóstico inicial foi de carcinoma de células basais em $87,4 \%$ dos casos e de carcinoma de células escamosas em $12 \%$. Estudos retrospectivos com tal abordagem demonstram uma evidência da agressividade biológica e recidiva no carcinoma basocelular, especialmente quando de localização na porção média ou intermediária do nariz, região do canto interno do olho, sulco retroauricular, região préauricular, área pré-orbitária e couro cabeludo ${ }^{1,14}$. Um dos problemas pode ser atribuído às ressecções mais conservadoras dos cirurgiões nessas áreas, somado à dificuldade de margem oncológica profunda nas regiões de sulco na face.

As recidivas locais apresentam índices variando de $12 \%$ a $45,7 \%$ 4,15. A incidência de metastatização do carcinoma basocelular é extremamente rara, atingindo índices de $0,002 \%$ em grandes centros terciários ${ }^{16}$. Os índices de metastatização regional dos carcinomas epidermóide, basocelular e do basoescamoso variam de $4 \%$ a $7,9 \%$, $0,09 \%$ a $0,4 \%$ e $6,1 \%$ a $8,6 \%$, respectivamente ${ }^{6,12}$. Podemos observar que as taxas de metástases foram baixas nos dois estudos. Provavelmente pelo número reduzido de casos, há uma dificuldade real de mensurar a metastatização, embora evidente o maior potencial de metástases do carcinoma basoescamoso.

A infiltração perineural é um evento incomum nos tumores malignos de pele $\mathrm{e}^{17}$, com incidência inferior a $5 \%$ dos $\operatorname{casos}^{18,19}$. Na presença de infiltração perineural presente no carcinoma basoescamoso, há maiores índice de morbi-mortalidade, denotando pior prognóstico, especialmente nas lesões localizadas da cabeça e pescoço ${ }^{17,19,20}$. Martin et $a^{R}$, demonstraram que o tumor misto com presence de infiltração perineural apresenta maiores índices de recidivas locais e metástases regionais, em relação aos pacientes com ausência de infiltração perineural. A infiltração perineural presente ao exame histológico tem incidência menor no tumor primário sem tratamento pré-

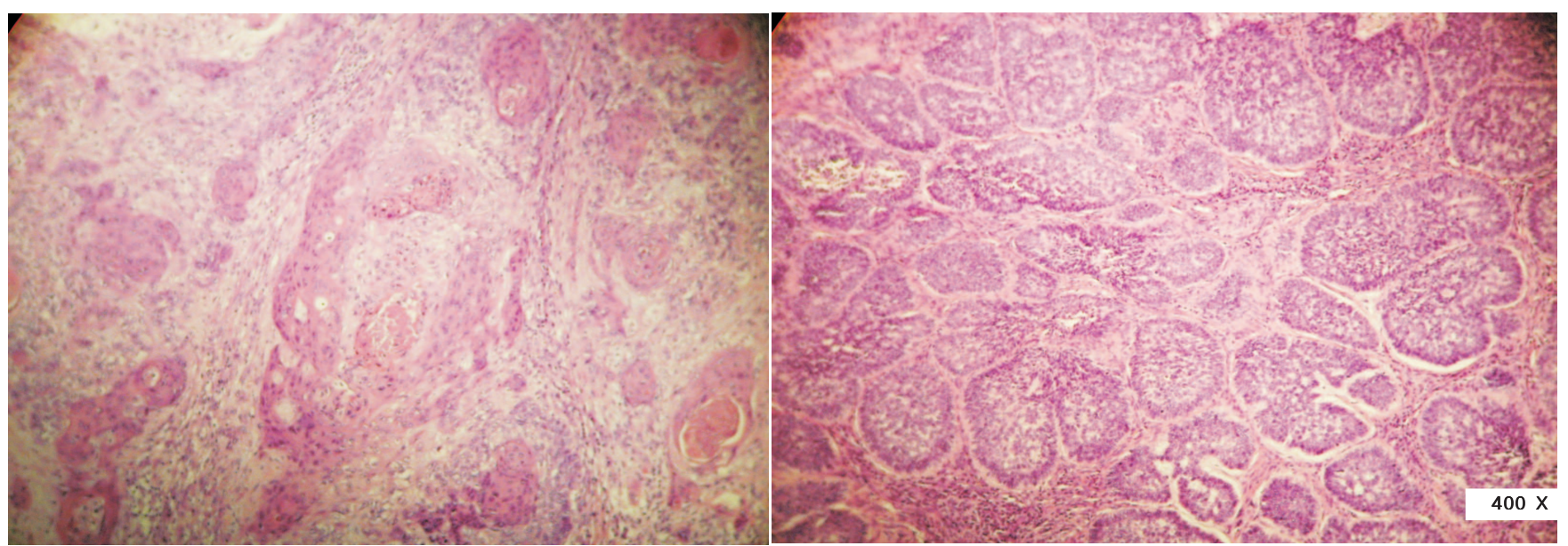

Figura 4 - Corte histológico representando a área de carcinoma epidermóide e carcinoma basocelular, através da coloração de HE. 
vio, sendo de $1 \%$ e de $2,5 \%$ a $14 \%$ no carcinoma epidermoide, denotando o comportamento natural de maior agressividade no carcinoma basoescamoso ${ }^{17}$. Vários casos com presença de infiltração perineural (69\%) ao exame histológico são recidivas locais de tumores previamente tratados ${ }^{13}$.

Outro fator de prognóstico desfavorável é a presença de linfonodos regionais comprometidos pela neoplasia. Sua presença implica em complementação cirúrgica com radioterapia. Num estudo de 250 recidivas de tumores malignos de pele na cabeça e pescoço, 70 (28\%) casos evoluíram com recidivas regionais. Na análise multivariada, os fatores determinados de pior evolução foram a presença de comprometimento linfonodal e margens cirúrgicas comprometidas pela neoplasia ${ }^{21}$.

As opções de tratamento do são cirurgia, cirurgia de Mohs e radioterapia. Em razão da maior recidiva local, o tratamento ideal é a cirurgia com margens amplas de segurança. Todavia, os maiores índices de recidiva local foram observados nas cirurgias com ressecções e margens amplas 2,6,12. Algumas séries demonstraram taxas de controle locais superior com a cirurgia de Mohs versus a ressecção cirúrgica tradicional, com $4 \%$ a $5 \%$ de recidiva local em cinco anos, especialmente nos casos de segunda recidiva ${ }^{12,22}$. A radioterapia frequentemente tem indicação no pós-operatótio e nos casos de infiltração perineural presente, não tendo eficácia comprovada após a cirurgia de Mohs ${ }^{17}$. Numa série mais recente, a cirurgia de Mohs apresentou controle local coincidente, todavia com aumento das metástases a distância ${ }^{8}$. As demais indicações de radioterapia são reservadas às lesões irressecáveis, ressecções incompletas e pacientes em condições clínicas precárias.

\section{A B S S T R A C T}

The collision or mixed tumor is a malignant neoplasm of the skin related to sun exposure and incidence rates of up to $1.5 \%$. It displays a distinctive clinical behavior in relation to other malignancies of the skin and the histological diagnosis, characterized by the collision between a basal cell carcinoma and squamous cell carcinoma, i.e., two malignancies with distinct histologies and sharp interface between them. The case reported was of a male, 73-year-old patient, with two cervical lesions progressively growing in recent months. The chosen treatment was surgery. Histological examination showed the presence of squamous cell carcinoma adjacent to basal cell carcinoma. These tumors preferentially occur in light-skinned men in the fifth or sixth decades of life. Their most common location is in the head and neck, especially in the central part of the face. The differential diagnosis of basal-squamous carcinoma is defined by distinct histological criteria, since both tumors have similar clinical behavior. Local recurrence rates vary from $12 \%$ to $45 \%$, whereas regional ones are of approximately $7.5 \%$. The main prognostic factors are gender, surgical margins, perineural infiltration and lymph node status. The treatment of choice is resection, radiotherapy being indicated as adjuvant or to inoperable lesions. Local recurrence is the main limiting factor in disease-free survival, with poor results.

Key words: Carcinoma, basosquamous. Skin neoplasms. Head and neck neoplasms.

\section{REFERÊNCIAS}

1. Nguyen AV, Whitaker DC, Frodel J. Differentiation of basal cell carcinoma. Otolaryngol Clin North Am 1993;26(1):37-56.

2. Martin RC 2nd, Edwards MJ, Cawte TG, Sewell CL, McMasters KM. Basosquamous carcinoma: analysis of prognostic factors influencing recurrence. Cancer, 2000;88(6):1365-9.

3. Santos OLR, Costa e Silva SCM, Gurgel PJC, Maceira JMP, Sodré CT, Perreira Jr. AC. Carcinoma basoescamoso pigmentado. An Bras Dermatol, 1994;69(1):22-6.

4. MacCormac $\mathrm{H}$. The relation of rodent ulcer to squamous cell carcinoma of the skin. Arch Middlesex Hosp 1910; 19:172-83.

5. Petri WH 3rd, Zoldos J, Wilson TM. Surgical management of basosquamous carcinoma with perineural invasion: report of case. J Oral Maxillofac Surg 1995;53(8):951-4.

6. Borel DM. Cutaneous basosquamous carcinoma. Review of the literature and report of 35 cases. Arch Pathol 1973;95(5):293-7.

7. Wade TR, Ackerman AB. The many faces of basal-cell carcinoma. J Dermatol Surg Ocol. 1978;4(1):23-8.

8. Bowman PH, Ratz JL, Knoepp TG, Barnes CJ, Finley EM. Basosquamous carcinoma. Dermatol Surg 2003; 29(8):830-2.; discussion 833

9. Farmer ER, Helwig EB. Metastatic basal cell carcinoma: a clinicopathologic study of seventeen cases. Cancer 1980;46(4):74857.

10. Miller SJ. Biology of basal cell carcinoma (Part I). J Am Acad Dermatol $1991 ; 24(1): 1-13$
11. Lennox $B$, Wells $A$. Diferentiation in the rodent ulcer groups of tumors. Br J Cancer 1951:5(2):195-212.

12. Schuller DE, Berg JW, Sherman G, Krause CJ. Cutaneous basosquamous carcinoma of the head and neck: a comparative analysis. Otolaryngol Head Neck Surg 1979;87(4):420-7.

13. Leibovitch I, Huilgol SC, Selva D, Richards S, Paver R. Basosquamous carcinoma: treatment with Mohs micrographic surgery. Cancer 2005;194(1):170-5.

14. Clark D. Cutaneous micrographic surgery. Otolaryngol Clin North Am 1993;26(2):185-202.

15. Karahan N, Baspinar S, Mehmet $Y$, Ibrahim B. The use of Ber-EP4 antigen in the differential diagnosis of basosquamous carcinoma from squamous and basal cell carcinoma. Türk Patoloji Dergisi 2006;22(2):87-91

16. Paver K, Poyzer K, Burry N, Deakin M. The incidence of basal cell carcinoma and their metastases in Australia and New Zealand. Australas J Dermatol 1973;14(1):53.

17. Feasel AM, Brown TJ, Bogle MA, Tschen JA, Nelson BR. Perineura invasion of cutaneous malignancies. Dermatol Surg 2001;27(6):53142.

18. Mendenhall WM, Amdur RJ, Williams LS, Mancuso AA, Stringer $\mathrm{SP}$, Mendenhall NP. Carcinoma of the skin of the head and neck with perineural invasion. Head Neck 2002;24(1):78-83.

19. McCord MW, Mendenhall WM, Parsons JT, Amdur RJ, Stringer SP, Cassisi NJ, Million RR. Skin cancer of the head and neck with clinical perineural invasion. Int J Radiat Oncol Biol Phys 2000;47(1):89-93. 
20. Matorin PA, Wagner RF Jr. Mohs micrographic surgery: technical difficulties posed by perineural invasion. Int J Dermato 1992;31(2):83-6.

21. Garcia C, Poletti E, Crowson AN. Basosquamous carcinoma. J Am Acad Dermatol 2009;60(1):137-43.

22. Leibovitch I, Huilgol SC, Selva D, Richards S, Paver R. Basosquamous carcinoma: treatment with Mohs micrographic surgery. Cancer 2005;104(1):170-5.

Recebido em 22/06/2010

Aceito para publicação em 30/08/2010

Conflito de interesse: nenhum

Fonte de financiamento: nenhuma

\section{Como citar este artigo:}

Chedid HM, Menezes AS, Aikawa KF, Lehn CN, Rapoport A, Mercante AMC, Curioni A. Tumor de colisão de pele de pescoço: nota técnica. Rev Col Bras Cir. [periódico na Internet] 2011; 38(1). Disponível em URL: http://www.scielo.br/rcbc

\section{Endereço para correspondência:}

Abrão Rapoport

E-mail: arapoport@terra.com.br 